\title{
Characterization of Protein Phosphatases Associated with the Particulate Fraction from Rat Liver
}

\author{
Kunimi Kikuchi, ${ }^{*} \dagger$ Shinri Tamura, $\ddagger$ Ryuzaburo \\ Shineha $\S$ and Shigeru Tsuiki* \\ * Biochemistry Laboratory, the Research Institute for \\ Tuberculosis and Cancer, Tohoku University, Sendai 980, \\ †Section of Biochemistry, Institute of Immunological \\ Science, Hokkaido University, Sapporo 060, $₫$ Department of \\ Biochemistry, Hirosaki University School of Medicine, \\ Hirosaki 036, and §the Second Department of Surgery, \\ Tohoku University School of Medicine, Sendai 980
}

Kikuchi, K., Tamura, S., Shineha, R. and Tsuiki, S. Characterization of Protein Phosphatases Associated with the Particulate Fraction from Rat Liver. Tohoku J. Exp. Med., 1990, 160 (4), 287-300_ Protein phosphatases associated with the particulate fraction from rat liver were studied by chromatographing the fraction on a DEAE-cellulose column and assaying the eluate with phosphorylase $a$ and glycogen synthase $\mathrm{D}$ as substrates. Phosphorylase phosphatase activity emerged as two peaks, termed P-1 and P-2 in order of elution, both of which were inhibited by $\mathrm{Mn}^{2+}$ and $\mathrm{Mg}^{2+}$. P-1 and P-2 were $M_{r}=50,000$ and 32,000 proteins, respectively, and when treated with trypsin, P-1 converted to a form indistinguishable from $\mathrm{P}-2$, to which protein phosphatase inhibitor-2 was a potent inhibitor. Thus P-2 appears to be the catalytic subunit of type-1 protein phosphatase even though it has been degrated proteolytically as evidenced by its relatively low $M_{r}$. The elution profile of glycogen synthase phosphatase activity was entirely different. The activity obtained with $5 \mathrm{mM} \mathrm{Mn}^{2+}$ resolved into three peaks, the second-migrating M-2 being the largest. M-2 is an $M_{r}=70,000$ protein; but an attempt to purify it has been unsuccessful giving a product of $M_{r}=40,000$ and closely similar to the type-1 catalytic subunit in properties including inhibition by inhibitor-2. These results suggest that phosphatases P-1 and M-2 have a common catalytic subunit (type-1), which is bound to different "regulatory" subunits. M-2 distributes in glycogen particles and microsomes evenly while P-1 is almost exclusively in microsomes.— protein phosphatase; glycogen synthase ; phosphorylase phosphatase ; rat liver; rat liver particulate fraction

The reversible phosphorylation/dephosphorylation reaction of enzymes has been recognized as an important mechanism, by which cellular functions are

Received December 22, 1989 ; revision accepted for publication February 27, 1990 Reprint requests should be addressed to Shigeru Tsuiki (Present address : Laboratory of Physiological Chemistry, Tohoku College of Pharmacy, Sendai 981). 
regulated (Cohen 1982). Although the dephosphorylation of various enzymes was initially thought to be catalyzed by a single non-specific protein phosphatase (Khandelwal et al. 1976; Killilea et al. 1976), the existence of multiple protein phosphatases with different substrate preferences was then noticed by us (Kikuchi et al. 1977) and in other laboratories (Devos and Hers 1974; Tan and Nuttall 1976). In rat liver cytosol, we were able to differentiate three forms, termed IA, IB and II, of protein phosphatase (Kikuchi et al. 1977; Tamura et al. 1978) and purified all of them to homogeneity (Tamura and Tsuiki 1980; Tamura et al. 1980 ; Hiraga et al. 1981). These studies also show that IA and II are the major (glycogen) synthase phosphatase and phosphorylase phosphatase, respectively, in rat liver cytosol. Cohen (1982), on the other hand, proposed a classification of protein phosphatases into types 1 and 2 . Type 2 phosphatase consists of three subclasses, namely $2 \mathrm{~A}, 2 \mathrm{~B}$ and $2 \mathrm{C}$, and our IA, IB and II appear to correspond to his $2 \mathrm{C}, 2 \mathrm{~A}_{1}$ and $2 \mathrm{~A}_{2}$, respectively.

In liver, the particulate fraction contains high levels of protein phosphatase (Goris et al. 1977; Tan and Nuttall 1978). Cohen and his coworkers (Alemany and Cohen 1986; Alemany et al. 1986; Schelling et al. 1988) and Stalmans and his coworkers (Mvumbi and Stalmans 1987 ; Bollen and Stalmans 1988 ; Bollen et al. 1988) agree on the conclusion that the enzyme can be clasisfied as type-1 protein phosphatase. It also appears that the particulate fraction of liver contains more than a single form of type-1 phosphatase (Bollen et al. 1988; Schelling et al. 1988), which should be distinguished from each other by the non-catalytic, or regulatory, subunit(s). None of these phosphatases, however, has been characterized.

In the present work, we report that the particulate fraction of rat liver possesses at least two distinct protein phosphatases (P-1 and M-2), which are most easily distinguished from each other by relative activities towards phosphorylase $a$ and (glycogen) synthase D. The results so far obtained suggest that they share the catalytic subunit of type-1 protein phosphatase (Ingebritsen et al. 1980; DePaori-Roach 1984) but probably possess non identical "regulatory" subunit(s). A preliminary report on this work has been published (Tsuiki et al. 1985).

\section{Materials and Methods}

\section{Liver}

All preparative operations were carried out at $0-4^{\circ} \mathrm{C}$. Male Donryu rats (150-200 g) were starved for 2 days, re-fed for 1 day and sacrificed by decapitation. Livers were quickly removed, rinsed in $0.15 \mathrm{M} \mathrm{NaCl}$ and homogenized for $2 \mathrm{~min}$ in 4 vol. of $0.5 \mathrm{M}$ sucrose/62.5 mM glycylglycine $(\mathrm{pH} 7.5) / 6.25 \mathrm{mM}$ EDTA using a glass/Teflon homogenizer. In some experiments, we used the homogenization buffer which contained a mixture of protease inhibitors: they were $2 \mathrm{mM}$ EGTA, $0.1 \mathrm{mM} N$-tosyl-L-lysyl chloromethyl-ketone (TLCK), $0.1 \mathrm{mM} \quad N$-tosyl-L-phenylalanyl chloromethyl-ketone (TPCK), $0.1 \mathrm{mM}$ phenylmethyl-sulfonyl fluoride (PMSF) and $0.5 \mathrm{mM}$ benzamidine. The particulate fraction was prepared by centrifuging the homogenate at $105,000 \times \mathrm{g}$ for $1 \mathrm{hr}$. The pellet was 
suspended in a minimum volume of buffer A (10 mM glycylglycine, $\mathrm{pH} 7.5 / 5 \mathrm{mM}$ mercaptoethanol $/ 2 \%, \mathrm{v} / \mathrm{v}$, glycerol), homogenized for 2 min using a glass/Teflon homogenizer, and used as the particulate fraction.

\section{Chromatography on DEAE-cellulose}

The particulate fraction from $10 \mathrm{~g}$ liver was applied onto a DEAE-cellulose column $(1.5 \times 12 \mathrm{~cm})$ previously equilibrated with buffer A. The column was washed with buffer A $(200 \mathrm{ml})$ and developed with a linear $0-0.5 \mathrm{M} \mathrm{NaCl}$ gradient in $200 \mathrm{ml}$ of buffer A. The eluate was dialyzed against buffer A as described previously (Tamura et al. 1980). Five ml fractions were collected and assayed for phosphorylase phosphatase and synthase phosphatase activities.

\section{Preparation of the glycogen and microsomal fractions}

Livers from 2 day-starved and 1 day-refed rats were homogenized as described above but using homogenization buffer containing protease inhibitors (see above). After centrifugation at $5,000 \times g$ for $20 \mathrm{~min}$, the supernatant was centrifuged at $50,000 \times g$ for 90 min. The supernatant was then centrifuged at $105,000 \times g$ for $1 \mathrm{hr}$. The pellet fractions obtained at $50,000 \times g$ and $105,000 \times g$ were rich in glycogen particles and microsomes, respectively, and they were used after suspension in buffer $\mathrm{A}$.

\section{Purification of phosphatase $M-2$}

In the chromatographic steps described below, the eluate was dialyzed against the equilibrating buffer as previously described (Tamura et al. 1980) before it was collected in fractions. Livers $(250 \mathrm{~g})$ from 2 days-starved and 1 day-refed rats were homogenized as above except homogenization buffer, which contained protease inhibitors (see above) and 40 $\mathrm{mM} \mathrm{NaF}$. The homogenate was centrifuged at $5,000 \times g$ for $20 \mathrm{~min}$ and the supernatant was further centrifuged at $50,000 \times \mathrm{g}$ for $90 \mathrm{~min}$. The pellet obtained at $50,000 \times g$ was suspended in $75 \mathrm{ml}$ of buffer B (20 mM Tris-HCl, $\mathrm{pH} 7.4 / 5 \mathrm{mM}$ mercaptoethanol/ $2 \%, \mathrm{v} / \mathrm{v}$, glycerol) and applied to a DEAE-celluloce column $(2.5 \times 10 \mathrm{~cm})$, previously equilibrated with buffer B. The column was washed with buffer B and developed with a linear $0-0.5 \mathrm{M} \mathrm{NaCl}$ gradient in $500 \mathrm{ml}$ of buffer B. The eluate was collected in $10 \mathrm{ml}$ fractions and assayed for synthase phosphatase activity. Fractions rich in synthase phosphatase activity were pooled and, after addition of $\mathrm{MnCl}_{2}$ to a final concentration of $1 \mathrm{mM}$, applied onto an aminohexyl-Sepharose-4B column $(1.5 \times 3 \mathrm{~cm})$ previously equilibrated with buffer $\mathrm{B} / 1 \mathrm{mM}$ $\mathrm{MnCl}_{2}$. The column was washed with the equilibrating bufer, and elution was performed with a linear 0-0.7 M NaCl gradient in $240 \mathrm{ml}$ of the same buffer. The eluate was collected in $10 \mathrm{ml}$ and assayed for synthase phosphatase activity. Fractions containing the activity were pooled and subjected to the second aminohexyl-Sepharose-4B chromatography. Fractions rich in synthase phosphatase activity were pooled and applied to a protamineSepharose-4B column $(1.5 \times 2 \mathrm{~cm})$ previously equilibrated with buffer $\mathrm{B} / 1 \mathrm{mM} \mathrm{MnCl}_{2}$. After washing with the equilibrating buffer, the column was developed with a linear 0-1.0 $\mathrm{M} \mathrm{NaCl}$ gradient in $100 \mathrm{ml}$ of the same buffer. The eluate was collected in $5 \mathrm{ml}$ and assayed for synthase phosphatase activity. Fractions containing the activity were pooled, concentrated to $1.5 \mathrm{ml}$ by usng Amicon YM5, applied to a Sephadex G-150 column $(2.5 \times 40 \mathrm{~cm})$ previously equilibrated with buffer $\mathrm{B} / 1 \mathrm{mM} \mathrm{MnCl} \mathrm{m}_{2}$ and eluted with the same buffer at a flow rate of $10 \mathrm{ml} / \mathrm{hr}$. Four $\mathrm{ml}$ fractions were collected and assayed for synthase phosphatase activity.

\section{Substrates}

Crystalline rabbit skeletal muscle phosphorylase $a$ was purchased from Boehringer (Mannheim, FRG). $\left.\quad{ }^{32} \mathrm{P}\right]$ Phosphorylase $a\left(0.2 \times 10^{5} \mathrm{cpm} / \mathrm{nmol}\right)$ was prepared after incubation of rabbit skeletal muscle phosphorylase $b$ (Boehringer, Mannheim, FRG) with $\left[\gamma^{-32} \mathrm{P}\right]$ ATP and phosphorylase kinase as described by Antoniw et al. (1977). Phosphorylase 
kinase was prepared from rabbit skeletal muscle by the method of Cohen (1973). Synthase D was purified from rat liver by the procedure described by Hiraga et al. (1981) except preparation of glycogen particles, which were washed with $0.5 \mathrm{M} \mathrm{KCl} / 10 \mathrm{mM}$ Tris-HCl $(\mathrm{pH}$ $7.75) / 5 \mathrm{mM}$ mercaptoethanol $/ 10 \%$ (v/v) glycerol $/ 1 \mathrm{mM}$ EDTA $/ 40 \mathrm{mM} \mathrm{NaF}$ prior to application onto DEAE-cellulose. The final solution was stored at $-70^{\circ} \mathrm{C}$ in the presence of $5 \mathrm{mg} / \mathrm{ml}$ rabbit liver glycogen.

\section{Protein phosphatase assays}

Phosphorylase phosphtase- and synthase phosphatase- activities were assayed by measuring the conversion of phosphorylase $a$ to phosphorylase $b$ and the formation of synthase I from synthase $\mathrm{D}$, respectively. Unless otherwise specified, the assay mixture for synthase phosphatase contained $5 \mathrm{mM} \mathrm{MnCl}$; no metal was required for phosphorylase phosphatase activity. The detailed procedures and the definition of the units of the enzymes were described by Kikuchi et al. (1977) and Tamura et al. (1980). In phosphorylase phosphatase assay, phosphorylase $a$ was sometimes replaced by $\left[{ }^{32} \mathrm{P}\right]$ phosphorylase $a$ : after incubation, the release of $\left.{ }^{32} \mathrm{P}\right]$ phosphate was measured as described by Tamura et al. (1978). Protein was determined by the method of Bradford (1976).

\section{Molecular weight determination}

Gel filtration on Sephadex G-150 or G-200 was used to determine the molecular weight of various protein phosphatases described below.

\section{Other materials}

Protein phosphatase inhibitor-2 was prepared from rabbit skeletal muscle according to Yang et al. (1981): the step-1 preparation was used. Sheep antibody against the $M_{r}=$ 33,000 catalytic subunit of rabbit skeletal muscle type-1 protein phosphatase (Brautigan et al. 1985) was a generous gift from Dr. D.L. Brautigan (Brown University, Providence, Rhode Island, USA). DEAE-cellulose (DE-52) was purchased from Whatman (Kent, UK) and aminohexyl-Sepharose-4B, Sephadex G-150 and Sephadex G-200 were the products of Pharmacia (Uppsalla, Sweden). Protamine-Sepharose-4B was prepared as described by Tamura et al. (1980). Novo heparin was obtained from Kodama (Kyoto).

\section{RESUlTS}

\section{Release of protein phosphatases from the particulate fraction}

In preliminary experiments, several procedures were applied to release protein phosphatases from the particulate fraction of rat liver. Phosphorylase phosphatase activity was readily released when $0.5 \mathrm{M} \mathrm{KCl}$ was included in the homogenizing buffer while under the same conditions, the bulk of synthase phosphatase activity remained unreleasable. Finally, it was found that both activities conld be released almost quantitatively by passing the particulate fraction through a DEAE-cellulose column. Under these conditions, Brij-35 had no effect on either the yield of phosphatase activities or their elution profile.

\section{Chromatography of the particulate fraction on $D E A E$-cellulose}

The particulate fraction of rat liver was chromatographed on DEAEcellulose. When the eluate was assayed in the absence of metals, phosphorylase phosphatase activity was found to be recovered in two peaks, which were then designated P-1 and P-2 in order of elution (Fig. 1a). In the presence of $5 \mathrm{mM}$ 

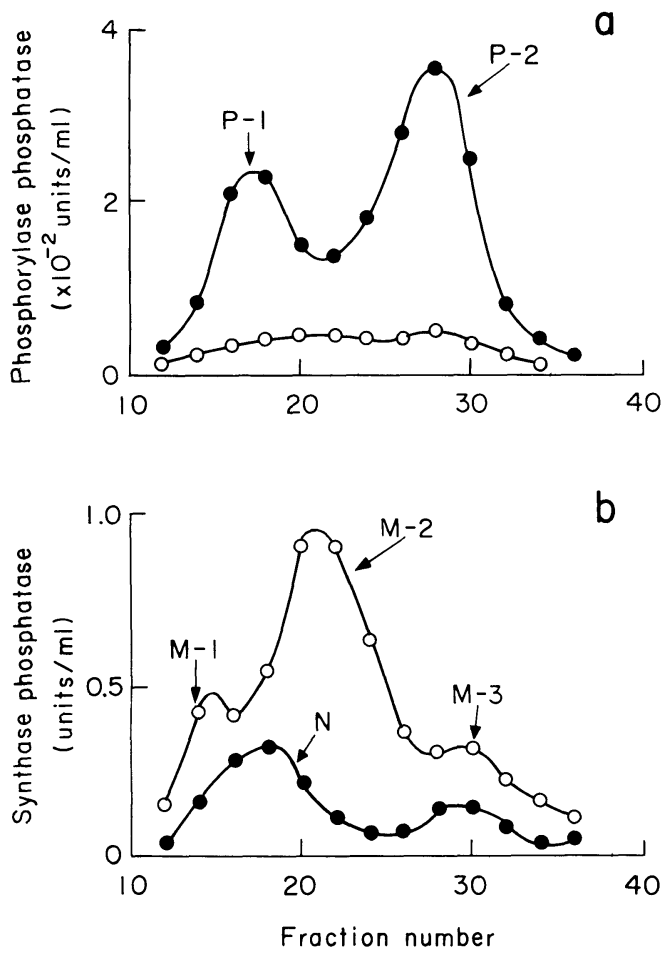

Fig. 1. Chromatography of particulate-associated protein phosphatases on DEAE-cellulose. The procedure was given in text. The eluate was assayed for phosphorylase phosphatase (a) and synthase phosphatase (b) in the absence $(\bullet)$ or presence $(\bigcirc)$ of $5 \mathrm{mM} \mathrm{MnCl} 2$.

$\mathrm{MnCl}_{2}$, no new peak was detected but the activities of P-1 and P-2 were suppressed almost completely.

The elution profile of synthase phosphatase activity was entirely different (Fig. 1b). When assayed in the absence of metals, only a single small peak, then designated $\mathrm{N}$, was found to coelute with P-1. The inclusion of $5 \mathrm{mM} \mathrm{MgCl} \mathrm{M}_{2}$ in the assay mixture did not much affect the elution profile (not shown). By far the highest activity of synthase phosphatase was obtained when $\mathrm{MnCl}_{2}$ was present, and we were able to differentiate in the elution diagram three peaks, designated M-1, M-2 and M-3 in order of elution, of which M-2 was the highest. None of these activity peaks coincided with any of previously known protein phosphatases.

The particulate fraction was also prepared in the presence of protease inhibitors, but these inhibitors did not alter the elution profile of protein phosphatases except that P-1 was somewhat increased while P-2 was somewhat decreased (see below). In all these experiments, none of the cytosolic protein phosphatases (IA, IB and II) was detected. 


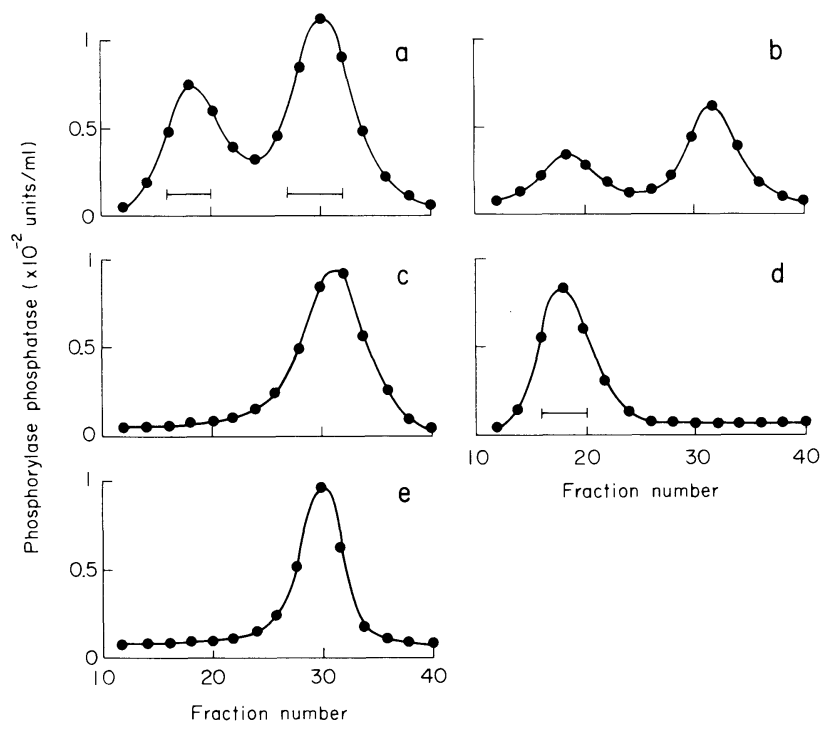

Fig. 2. Rechromatography of phosphatases P-1 and P-2 on DEAE-cellulose. The conditions for chromatography are the same as described in text. $a$, The particulate fraction prepared as described in text (but from $5 \mathrm{~g}$ of liver) was chromatographed ; $b$, fractions $16-20$ in $a$ (indicated by bar) were pooled and rechromatographed; $c$, fractions 27-32 in $a$ (indicated by bar) were pooled and rechromatographed; $d$, fractions corresponding to 16-20 of $a$ but from the particulate fraction prepared in the presence of protease inhibitors (see text) were pooled and rechromatographed; and $e$, fractions $16-20$ in $d$ (indicated by bar) were pooled, incubated with $0.25 \mathrm{mg} / \mathrm{ml}$ of trypsin for $30 \mathrm{~min}$ at $30^{\circ} \mathrm{C}$ and, after the removal of trypsin by using an aminohexyl-Sepharose4B column, rechromatographed.

\section{Further characterization of phosphorylase phosphatase activity}

When P-1 and P-2 (Fig. 2a) were separately rechromatographed on DEAEcellulose, a substantially large portion of P-1 emerged at the position of P-2 (Fig. $2 \mathrm{~b}$ ), whereas P-2 eluted exclusively at the original position (Fig. 2c). P-1 obtained from the particulate fraction prepared in the presence of protease inhibitors, on the other hand, did not convert to P-2 on rechromatography (Fig. 2d), and this P-1 was digested with trypsin. After the treatment, there was an approximately 2-fold increase in phosphorylase phosphatase activity, and now all the activity emerged at the position of P-2 as a sharp single peak (Fig. 2e). The trypsinization of P-1 also resulted in a decrease in its molecular weight from 50,000 to 32,000 . These results suggest that P-2 is derived from P-1 by limited proteolysis.

Properties of phosphatases $P-1$ and $P-2$

Cytosolic protein phosphatases IB and II are known to contain a catalytic 

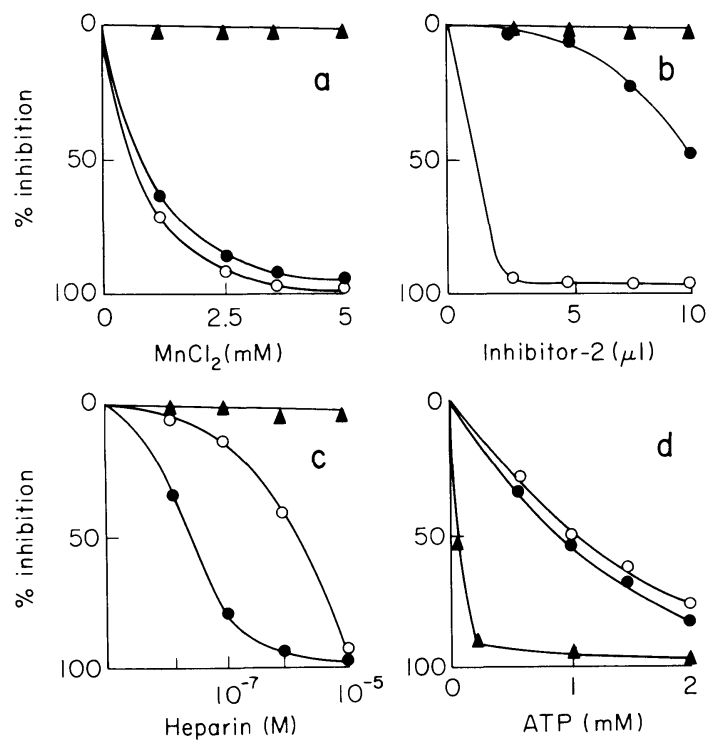

Fig. 3. Effects of increasing concentrations of $\mathrm{MnCl}_{2}$ (a), protein phosphatase inhibitor-2 (b), heparin (c) and ATP (d) on the $\alpha$-subunit of cytosolic

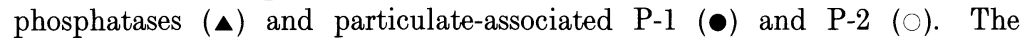
$\alpha$-subunit of phosphatase II was prepared by treating the holo-enzyme with mercaptoethanol (Tamura et al. 1980). P-1 was purified by chromatographing "stable" P-1 (see text) on Sephadex G-200. Trypsinized P-1 was used as P-2 after purification by chromatography on Sephadex G-200. All the assays were made in the absence of metals unless described otherwise.

subunit named $\alpha$, whose molecular weight is about 35,000 (Tamura and Tsuiki 1980 ; Tamura et al. 1980). Fig. 3 shows the comparison of P-1, P-2 (trypsinized $\mathrm{P}-1)$ and the $\alpha$-subunit from cytosolic phosphatase II on several properties. The activity of P-1 and P-2 were inhibited by $\mathrm{Mn}^{2+}$ (Fig. 3a), $\mathrm{Mg}^{2+}$ (not shown), protein phosphatase inhibitor-2 (Fig. 3b) and heparin (Fig. 3c), while none of them inhibited the $\alpha$-subunit. P-1 and P-2 were also distinguished from the $\alpha$-subunit in that ATP inhibition was slighter than that of the $\alpha$-subunit (Fig. 3d). Inhibition by $\mathrm{Mn}^{2+}$ (Silberman et al. 1984), inhibitor-2 (Huang and Glinsman 1976; Ingebritsen and Cohen 1983) and heparin (Gergely et al. 1984), together with a relatively low sensitivity to ATP inhibition (Tamura and Tsuiki 1980 ; Tamura et al. 1980), has been shown to be the characteristic features of protein phosphatases classified by Cohen (1982) as type-1. When compared with P-1, P-2 was more sensitive to inhibitor-2 but less sensitive to heparin. It is therefore possible that P-1 may be a hetero-dimeric molecule, in which a "regulatory" subunit serves to lower the sensitivity to inhibitor-2 of the type-1 catalytic subunit. P-2 appears to be a proteolytic product of the catalytic subunit (Silberman et al. 1984 ; Alemany et al. 1986). 


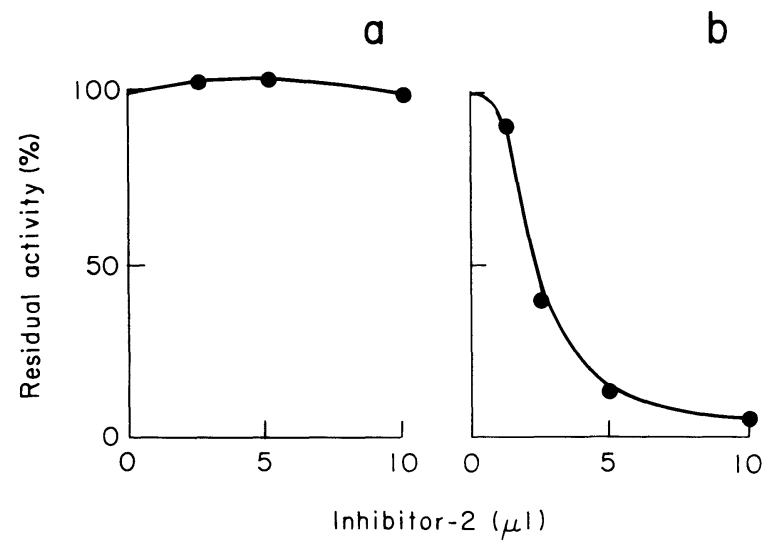

Fig. 4. Effect of increasing concentrations of protein phosphatase inhibitor-2 on the synthase phosphatase activity of phosphatase M-2. (a) Phosphatase M-2 of Fig. 1b; and (b) "the purified M-2".

\section{Further characterization of synthase phosphatases}

The elution profile of $\mathrm{Mn}^{2+}$-dependent synthase phosphatase activity from DEAE-cellulose is not very reproducible: we have found that increasing the rate of elution brings about a partial and reversible conversion of M-2 to M-1, although no alteration occurs in the relative yield of P-1 and P-2. When M-2 was further chromatographed on aminohexyl-Sepharose-4B, on the other hand, M-3 emerged besides M-2 whereas no M-2 was formed upon rechromatography of M-3. These results suggest that $\mathrm{M}-2$ may be the native form of $\mathrm{Mn}^{2+}$-dependent synthase phosphatase. We therefore decided to deal chiefly with M-2 in the studies that followed.

When M-2 was further chromatographed on Sephadex G-200, a single peak of synthase phosphatase activity emerged with an elution volume corresponding to $M_{r}=70,000$. The activity was dependent on $\mathrm{Mn}^{2+}$ but not on $\mathrm{Mg}^{2+}$, and a maximum activity was attained at $5 \mathrm{mM} \mathrm{Mn^{2+ }}$. M-2 was not inhibited by protein phosphatase inhibitor-2 (Fig. 4a).

Distribution of phosphatases $P-1$ and $M-2$ between glycogen particles and microsomes

Rat liver particulate fraction prepared as above consists mainly of glycogen particles and microsomes. To determine the location of phosphatases P-1 and M-2 more precisely, the glycogen and microsomal fractions were separately prepared and each fraction was chromatographed on DEAE-cellulose. The results obtained are such that M-2 distributes in the glycogen and microsomal fractions almost evenly while more than $70 \%$ of P-2 is present in the latter fraction. 
TABLE 1. Purification of synthase phosphatase $M-2$ from rat liver glycogen particles

\begin{tabular}{|c|c|c|c|c|c|c|c|}
\hline \multirow[b]{2}{*}{$\begin{array}{l}\text { Purification } \\
\text { steps }\end{array}$} & \multirow[b]{2}{*}{ Protein } & \multirow[b]{2}{*}{ Activity } & \multirow[b]{2}{*}{$\begin{array}{l}\text { Specific } \\
\text { activity }\end{array}$} & \multirow[b]{2}{*}{$\begin{array}{l}\text { Purifi- } \\
\text { cation }\end{array}$} & \multirow[b]{2}{*}{ Recovery } & \multicolumn{2}{|c|}{ Activity ratio } \\
\hline & & & & & & $\begin{array}{l}+\mathrm{Mn} / \\
-\mathrm{Mn}^{\mathrm{a}}\end{array}$ & $\overline{\mathrm{P} / \mathrm{SP}^{\mathrm{b}}}$ \\
\hline & (mg) & (units) & (units/mg) & (fold) & $(\%)$ & & \\
\hline DEAE-cellulose & 6.72 & 0.565 & 0.0841 & 1 & 100 & 2.6 & 45 \\
\hline $\begin{array}{l}\text { Aminohexyl- } \\
\text { Sepharose 4B }\end{array}$ & 2.04 & 0.242 & 0.119 & 1.4 & 43 & 1.1 & 77 \\
\hline $\begin{array}{l}\text { Aminohexyl- } \\
\text { Sepharose 4B (II) }\end{array}$ & 1.12 & 0.141 & 0.125 & 1.5 & 25 & 0.9 & 113 \\
\hline $\begin{array}{l}\text { Protamine- } \\
\quad \text { Sepharose 4B }\end{array}$ & 0.33 & 0.063 & 0.191 & 2.3 & 11 & 1.0 & 180 \\
\hline Sephadex G-150 & 0.015 & 0.0052 & 3.47 & 41.3 & 0.9 & 1.0 & 275 \\
\hline
\end{tabular}

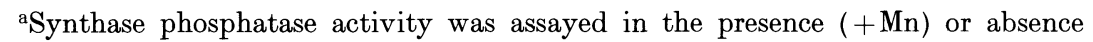
(- Mn) of $5 \mathrm{mM} \mathrm{MnCl}_{2}$.

${ }^{\mathrm{b}}$ The activities of phosphorylase phosphatase (PP) and synthase phosphatase (SP) were assayed in the presence of $5 \mathrm{mM} \mathrm{MnCl}$.

Purification and characterization of phosphatase $M-2$

M-2 associated with the glycogen fraction was purified by sequential chromatographies as described under Materials and Methods. The purification except for the first DEAE-cellulose step was conducted in the presence of $1 \mathrm{mM}$ $\mathrm{Mn}^{2+}$. The metal stabilized the enzyme activity considerably, and at the same time, it rendered the enzyme no longer dependent on $\mathrm{Mn}^{2+}$ (see Table 1). At any step of the purification, synthase phosphatase activity emerged as a single (though somewhat broad) peak, and the pooled peak fractions were subjected to the following step. Despite all these cautions, however, M-2 was considerably modified in the course of purification, as exemplified by the phosphorylate phosphatase/synthase phosphatase activity ratio being increased with the progress of purification (Table 1). If $\mathrm{Mn}^{2+}$ is excluded from the assay mixture, even a higher value than that of Table 1 would be expected for the activity ratio of the most highly purified preparetion, then tentatively called "the purified M-2", since the phosphorylase phosphatase activity of this preparation has been found to be inhibited by $\mathrm{Mn}^{2+}$ (not shown in the Table). The purification also reduced the size of M-2. "The purified M-2" emerged from a Sephadex G-150 column with an elution volume corresponding to $\boldsymbol{M}_{r}$ not greater than 40,000. Finally, "the purified M-2" was found to be inhibited by inhibitor-2 (Fig. 4b). Since M-2 was totally insensitive to this inhibition before purification (Fig. 4a), the purification appears to have eliminated a portion of the phosphatase, which is responsible for the insensitivity to the inhibition.

It is therefore probable that like $\mathrm{P}-1, \mathrm{M}-2$ is a type- 1 protein phosphatase, in which the catalytic subunit of type-1 protein phosphatase is complexed to a 


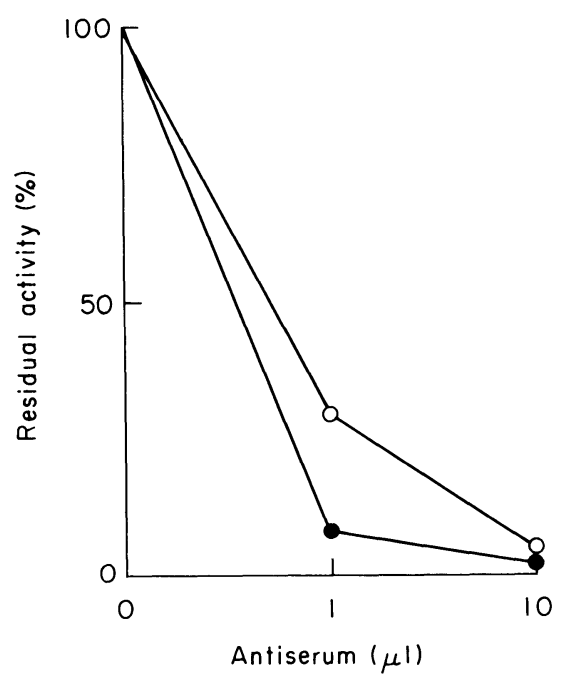

Fig. 5. Inhibition of phosphatase P-2 $(\bullet)$ and "the purified phosphatase M-2" $(O)$ by sheep anti-serum against the type-1 catalytic subunit.

"regulatory" subunit forming a holoenzyme of $M_{r} 70,000$. M-2 possesses the type-1 catalytic subunit as indicated by the observation that "the purified M-2" is inhibited by inhibitor-2, exhibits a marked preference for phosphorylase to synthase and has a molecular weight close to 38,000 , the reported $M_{r}$ of the type- 1 catalytic subunit (Ballow et al. 1983; Tung et al. 1984 ; DeGuzman and Lee 1988). Furthermore, as shown in Fig. 5, "the purified M-2" as well as P-2 is inhibited by sheep antiserum against rabbit skeletal muscle type-1 catalysic subunit (Brautigan et al. 1985). However, this antiserum had not ability to inhibit cytosolic protein phosphatase such as IA and II (data not shown).

\section{Discussion}

While some enzymatic properties of protein phosphatases associated with the particulate fraction of rat liver are entirely different from those of the enzymes in the cytosolic fraction, the two fractions are alike in that added phosphorylase and synthase are dephosphorylated by protein phosphatases distinct from each other. Thus the metal-inhibited protein phosphatase $\mathrm{P}-1$ and the $\mathrm{Mn}^{2+}$-activated protein phosphatase M-2 have been detected as the major phosphorylase phosphatase and synthase phosphatase, respectively, in the particulate fraction, although their true substrates have yet to be indentified.

In addition to the behavior to divalent cations and the substrate specificity, the two protein phosphatases differ in a number of respects. Phosphatase P-1 ( $M_{r}$ $50,000)$ is associated with microsomes, and it releases from them by washing with salt. Phosphatase M-2 $\left(M_{r} 70,000\right)$ distributes both in the glycogen and microsomal fractions, and it is unreleasable with salt. Despite these differences, P-1 
and M-2 must be type-1 protein phosphatases having a type-1 catalytic subunit. It should, however, be noted that at least two very closely related type-1 catalytic subunits exist in rabbit skeletal muscle (Cohen 1989). These two phosphatases probably differ in the non-catalytic, or "regulatory", subunit(s) bound to the catalytic subunit.

P-2 appears to be a proteolyzed type-1 catalytic subunit and arises from P-1 during the tissue homogenization and/or subsequent chromatography on DEAEcellulose (Figs. $1 \mathrm{~b}$ and $2 \mathrm{a}$ ). A limited proteolysis of P-1 may facilitate the release of the type-1 catalytic subunit, which may subsequently be proteolyzed to give $\mathrm{P}-2$, since the conversion of P-1 to P-2 is suppressed in the presence of protease inhibitors (Fig. 2d). An attempt to achieve an extensive purification of phosphatase M-2, on the other hand, resulted in a conversion of the phosphatase into an $M_{r}=40,000$ protein ("the purified M-2"), which was found to resemble P-2 in many respects but the molecular weight. We are at present unable to answer the question of how M-2 was converted to "the purified M-2" during its purification. It is, however, highly probable that proteases attack the putative regulatory subunit(s) of M-2 while the subunit is in firm association with the catalytic subunit. This mechanism well explains why the phosphorylase phosphatase/ synthase phosphatase activity ratio is gradually increased in the course of purification even though synthase phosphatase activity emerges as a single peak at every step of purification. It would also explain why the molecular weight of "the purified M-2" is somewhat larger than that of intact type-1 catalytic subunit. It is interesting to note that the G-protein, which mediates binding of rabbit skeletal muscle type-1 phosphatase to glycogen, is remarkably sensitive to proteolysis so that it is extensively fragmented during purification (Hiraga et al. 1987). The nature of $\mathrm{M}-1$ and $\mathrm{M}-3$, minor species of $\mathrm{Mn}^{2+}$-activated protein phosphatase, has yet to be established. Chromatographic analysis of the particulate fraction, however, revealed that M-2 is convertible reversibly to M-1: this suggests that M-1 may be an artifactual complex of M-2 with other molecules such as glycogen fragments.

Of the protein phosphatases described in the present paper, P-1 may be the same enzyme as previously described phosphorylase phosphatase of dog liver (Goris et al. 1977) : the latter enzyme is also an $M_{r}=50,000$ protein and inhibited by $\mathrm{Mn}^{2+}$. Although the nature of the regulatory subunit(s) making up P-1 together with the type-1 catalytic subunit remains to be seen, it may be a protein acting to lower the sensitivity of the catalytic subunit to inhibitor-2, since P-1 is much less susceptible than P-2 to this inhibition (Fig. 3b). A protein possessing a similar property has been purified by Goris et al. (1984) from the glycogen fraction of dog liver.

Comparison of the properties of phosphatase M-2 with those of the type-1 catalytic subunit suggests that phosphatase M-2 may possess a regulatory subunit that increases the affinity of the catalytic subunit for synthase D. It is therefore 
possible that phosphatase M-2 may function as a physiological synthase phosphatase. Additional lines of evidence supportting this view are: (i) a large portion of phosphatase M-2 distributes in the glycogen fraction (see above); and (ii) the synthase phosphatase activity of phosphatase M-2 is regulated in a biphasic manner by exogenous glycogen (Tsuiki et al. 1985). Recently, Schelling et al. (1988) have reported that in rat liver, type-1 protein phosphatase associated with glycogen can be distinguished from the microsomal enzyme by its lower phosphorylase phosphatase/synthase phosphatase activity ratio and inability to be released with salt. Currently, however, it is still uncertain whether or not the two groups study the same enzyme.

Although the activity of M-2 solubilized from the particulate fraction by DEAE-cellulose chromatography is dependent on $\mathrm{Mn}^{2+}$ (Fig. lb), the same enzyme does not require $\mathrm{Mn}^{2+}$ if it is still being associated with the particulate fraction unless the homogenization buffer contains $\mathrm{NaF}$ (unpublished data). It is also remarkable that the inclusion of $1 \mathrm{mM} \mathrm{MnCl}$ in purification buffers results in a reconversion of phosphatase M-2 to an $\mathrm{Mn}^{2+}$-independent form (Table 1). It is therefore likely that if M-2 is functioning intracellularly, endogenous metal(s) is probably sufficient to express its activity. In this respect, M-2 is distinct from cytosolic phosphatase IA, which requires exogenous $\mathrm{Mg}^{2+}$ or $\mathrm{Mn}^{2+}$ at any time and in any state (Hiraga et al. 1981).

The present paper has lent support to the currently growing view that more than a single forms of type-1 protein phosphatase exist in the particulate fraction of rat liver (Bollen et al. 1988; Schelling et al. 1988). In addition to phosphatases P-1 and M-2, we have quite recently identified a third type of type-1 protein phosphatase, tentatively designated phosphatase $\mathrm{N}$, in the particulate fraction by its metal-independent synthase phosphatase activity. While the level of phosphatase $\mathrm{N}$ in normal liver is quite low (see Fig. 1b), the enzyme is increased remarkably when the cells acquire proliferating activity. The preparation and characterization of this phosphatase, however, will be described elsewhere.

\section{References}

1) Alemany, S. \& Cohen, P. (1986) Phosphorylase $a$ is an allosteric inhibitor of the glycogen and microsomal forms of rat hepatic protein phosphatase-1. FEBS Lett., 198, 194-202.

2) Alemany, S., Pelech, S., Brierley, C.H. \& Cohen, P. (1986) The protein phosphatases involved in cellular regulation. Evidence that dephosphorylation of glycogen phosphorylase and glycogen synthase in the glycogen and microsomal fractions of rat liver are catalyzed by the same enzyme: Protein phosphatase-1. Eur. J. Biochem., 156, 101-110.

3) Antoniw, J.F., Nimmo, H.G., Yeaman, S.J. \& Cohen, P. (1977) Comparison of the substrate specificities of protein phosphatases involved in the regulation of glycogen metabolism in rabbit skeletal muscle. Biochem. J., 162, 423-433.

4) Ballow, L.M., Brautigan, D.L. \& Fischer, E.H. (1983) Subunit structure and activation of inactive phosphorylase phosphatase. Biochemistry, 22, 3393-3399. 
5) Bollen, M. \& Stalmans, W. (1988) The modulator protein dissociates the catalytic subunit of hepatic protein phosphatase G from glycogen. Biochem. J., 250, 659-663.

6) Bollen, M., Vandenheede, J.R. \& Stalmans, W. (1988) Characterization of glycogen synthase phosphatase and phosphorylase phosphatase in subcellular fractions. Biochim. Biophys. Acta, 969, 66-77.

7) Bradford, M.M. (1976) A rapid and sensitive method for the quantitation of microgram quantities of protein utilizing the principle of protein-dye binding. Anal. Biochem., 72, 248-254.

8) Brautigan, D.L., Shriner, C.L. \& Gruppuso, P.A. (1985) Phosphorylase phosphatase catalytic subunit. Evidence that the $M_{r}=33,000$ enzyme fragment is derived from a native protein of $M_{r}=70,000 . \quad J$. Biol. Chem., 260, 4295-4302.

9) Cohen, P. (1973) The subunit structure of rabbit-skeletal-muscle phosphorylase kinase and the molecular basis of its activation reaction. Eur. J. Biochem., 34, 1-14.

10) Cohen, P. (1982) The role of protein phosphorylation in neural and hormonal control of cellular activity. Nature, 296, 611-620.

11) Cohen, P. (1989) The structure and regulation of protein phosphatases. Ann. Rev. Biochem., 58, 453-508.

12) DeGuzman, A. \& Lee, E.Y.C. (1988) Preparation of low molecular weight forms of skeletal muscle protein phosphatase. Methods Enzymol., 159, 356-368.

13) DePaori-Roach, A.A. (1984) Synergistic phosphorylation and activation of ATPMg-dependent phosphoprotein phosphatase by Fa/GSK-3 and casein kinase II. $J$. Biol. Chem., 259, 12144-12152.

14) Devos, P. \& Hers, H.-G. (1974) Glycogen metabolism in the liver of the fetal rat. Biochem. J., 140, 331-340.

15) Gergely, P., Erdodi, F. \& Bot, G. (1984) Heparin inhibits the activity of protein phosphatase-1. FEBS Lett., 132, 293-295.

16) Goris, J., Defreyn, G. \& Merlevede, W. (1977) Multiple molecular forms of phosphorylase phosphatase associated with particulate glycogen and extracted from the cytosol of dog liver. Biochimie, 59, 171-178.

17) Goris, J., Waelkens, E., Camps, T. \& Merlevede, W. (1984) Regulation of protein phosphatase activity by the deinhibitor protein. Adv. Enzyme Regul., 22, 467-484.

18) Hiraga, A., Kikuchi, K., Tamura, S. \& Tsuiki, S. (1981) Purification and characterization of $\mathrm{Mg}^{2+}$-dependent glycogen synthase phosphatase (phosphoprotein phosphatase IA) from rat liver. Eur. J. Biochem., 119, 503-510.

19) Hiraga, A., Kemp, B.E. \& Cohen, P. (1987) Further studies on the structure of the glycogen-bound form of protein phosphatase-1 from rabbit skeletal muscle. Eur. $J$. Biochem., 163, 253-258.

20) Huang, F.L. \& Glinsman, W.H. (1976) Separation and characterization of two phosphorylase phosphatase inhibitors from rabbit skeletal muscle. Eur. J. Biochem., 70, $419-426$.

21) Ingebritsen, T.S. \& Cohen, P. (1983) Protein phosphatases: Properties and role in cellular regulation. Science, 221, 331-338.

22) Ingebritsen, T.S., Foulkes, J.G. \& Cohen, P. (1980) The broad specificity protein phosphatase from mammalian liver. Separation of the $M_{r}=35,000$ catalytic subunit into two distinct enzymes. FEBS Lett., 119, 9-14.

23) Khandelwal, R.K., Vandenheede, J.R. \& Krebs, E.G. (1976) Purification, properties, and substrate specificities of phosphoprotein phosphatase(s) from rabbit liver. $J$. Biol. Chem., 251, 4850-4858.

24) Kikuchi, K., Tamura, S., Hiraga, A. \& Tsuiki, S. (1977) Glycogen synthase phosphatase of rat liver. Its separation from phosphorylase phosphatase on DE-52 columns. Biochem. Biophys. Res. Commun., 75, 29-37.

25) Killilea, S.D., Brandt, H., Lee, E.Y.C. \& Whelan, W.J. (1976) Evidence for the coordinate control of activity of liver glycogen synthase and phosphorylase by a 
phosphoprotein phosphatase. J. Biol. Chem., 251, 2363-2368.

26) Mvumbi, L. \& Stalmans, W. (1987) High-affinity binding of glycogen-synthase phosphatases to glycogen particles in the liver. Biochem. J., 246, 367-374.

27) Schelling D., Leader, D.P., Zammit, V.A. \& Cohen, P. (1988) Distinct type-1 protein phosphatases are associated with hepatic glycogen and microsomes. Biochim. Biophys. Acta, 927, 221-231.

28) Silberman, S.R., Spech, M., Nemani, R., Ganapathi, M.K., Dombradi, V., Paris, H. \& Lee, E.Y.C. (1984) Isolation and characterization of rabbit skeletal muscle protein phosphatases C-I and C-II. J. Biol. Chem., 259, 2913-2922.

29) Tamura, S. \& Tsuiki, S. (1980) Purification and subunit structure of rat liver phosphoprotein phosphatase, whose molecular weight is 260,000 by gel filtration (phosphatase IB). Eur. J. Biochem., 111, 217-224.

30) Tamura, S., Kikuchi, K., Hiraga, A., Kikuchi, H., Hosokawa, M. \& Tsuiki, S. (1978) Characterization of multiple forms of histone phosphatase in rat liver. Biochim. Biophys. Acta, 524, 349-356.

31) Tamura, S., Kikuchi, H., Kikuchi, K., Hiraga, A. \& Tsuiki, S. (1980) Purification and subunit structure of high-molecular-weight phosphoprotein phosphatase (phosphatase II) from rat liver. Eur. J. Biochem., 104, 347-355.

32) Tan, A.W.H. \& Nuttal, F.Q. (1976) Regulation of synthase phosphatase and phosphorylase phosphatase in rat liver. Biochim. Biophys. Acta, 445, 118-130.

33) Tan, A.W.H. \& Nuttall, F.Q. (1978) Evidence for the non-identity of proteins having synsthase phosphatase, phosphorylase phosphatase and histone phosphatase activity in rat liver. Biochim. Biophys. Acta, 522, 139-150.

34) Tsuiki, S., Kikuchi, K., Tamura, S., Hiraga, A. \& Shineha, R. (1985) Glycogen synthase phosphatase and phosphorylase phosphatase of rat liver. Adv. Prot. Phosphatases, 1, 195-214.

35) Tung, H.Y.L., Resink, T.J., Hemmings, B., Shenoliker, S. \& Cohen, P. (1984) The catalytic subunits of protein phosphatase-1 and protein phosphatase-2A are distinct gene products. Eur. J. Biochem., 138, 625-641.

36) Yang, S.-D., Vandenheede, J.R. \& Merlevede, W. (1981) A simplified procedure for the purification of the protein phosphatase modulator (inhibitor-2) from rabbit skeletal muscle. FEBS Lett., 133, 293-295. 